\title{
Evapotranspiração de referência mensal para o Estado do Piauí
}

\author{
Adriano A. N. Gomes ${ }^{1}$, Aderson S. de Andrade Júnior² \& Raimundo M. de Medeiros ${ }^{3}$ \\ ${ }^{1}$ DEAg/UFCG. Av. Duque de Caxias, 5650 B. Buenos Aires, CEP 64006-220, Teresina, PI. E-mail: gomezxale@yahoo.com.br (Foto) \\ 2 Embrapa Meio Norte, Av. Duque de Caxias, 5650 B. Buenos Aires, CEP: 64006-220, Teresina, PI. Fone: (86) 3225 \\ 1141 Ramal 255. E-mail: aderson@cpamn.embrapa.br \\ ${ }^{3}$ SEMAR - Secretaria Estadual de Meio Ambiente e dos Recursos Naturais - PI, Rua Desembargador Freitas, 1599, CEP: \\ 64000-240, Teresina, PI. E.mail: mainarmedeiros@hotmail.com.br
}

Protocolo 188 - 28/11/2003 - Aprovado em 13/4/2005

\begin{abstract}
Resumo: $\mathrm{O}$ objetivo deste trabalho foi estimar a evapotranspiração de referência (ETo) mensal para o Estado do Piaú, pelo método empírico de Thornthwaite (1948), com base nas equações de estimativa da temperatura média do ar, propostas por Lima \& Ribeiro (1998). Estimou-se a ETo para os 222 municípios do Estado, cujos valores foram geoespacializados e agrupados em classes de ETo, com intervalo de $25 \mathrm{~mm}$, gerando-se mapas de ETo mensais. Os valores de ETo mensais variaram de 55,4 a $212,0 \mathrm{~mm}$, evidenciando a variação na demanda evapotranspirativa das diversas regiões do Estado. $O$ período de fevereiro a julho apresentou os menores valores mensais de ETo, enquanto de setembro a dezembro, os maiores valores. Esta tendência é um reflexo da variação espacial da temperatura média do ar mensal nas diferentes regiões do Estado.
\end{abstract}

Palavras-chave: planejamento agrícola, balanço hídrico, demanda hídrica, irrigação

\section{Monthly reference evapotranpiration for the State of Piaui, Brazil}

\begin{abstract}
The objective of this work was to estimate the mean monthly reference evapotranspiration (ETo) for Piaui State, Brazil. The ETo estimates were performed by the Thornthwaite's (1948) empirical method, based on estimated mean air temperature equations developed by Lima \& Ribeiro (1998). The ETo was estimated for 222 municipalites of Piaui State. The values were arranged in a spatial distribution and grouped in classes with $25 \mathrm{~mm}$ interval. Maps of monthly ETo were prepared. The monthly ETo values ranged from 55.4 to $212.0 \mathrm{~mm}$, showing large evapotranspiration variation among the several regions of Piaui State. Lower monthly ETo values were obtained for the period of February to July, while the higher values were observed for September to December. The spatial distribution of the monthly ETo values occurred as a function of the spatial variation of the monthly mean air temperature in the different regions of Piaui State.
\end{abstract}

Key words: agricultural planning, irrigation, water demand, water balance

\section{INTRODUÇÃO}

A agricultura é uma atividade econômica que por estar sujeita à variabilidade do clima, do mercado e da política agrária, torna-se instável e de alto risco, devendo ser bem planejada para garantir o seu sucesso. Entre todas as atividades econômicas, é a que mais depende das condições climáticas, sendo esta variável responsável por 60 a 70\% da variabilidade final da produção (Ortolani \& Camargo, 1987).

O Estado do Piauí apresenta duas estações bem definidas: uma chuvosa e outra seca. É caracterizada por três regimes pluviométricos: i) região sul, de novembro a março; ii) região central, de dezembro a abril e iii) região norte, de janeiro a maio. Nesses períodos as chuvas são superiores a $1000 \mathrm{~mm}$ em, aproximadamente, $48 \%$ do território piauiense (Medeiros, 1996). Entretanto, para o restante dos meses ocorre redução significativa nas cotas pluviométricas, destacando-se agosto e setembro como os mais críticos. Durante a estação chuvosa as precipitações não são uniformemente distribuídas.

Devido às suas características climáticas, a prática da irrigação torna-se fundamental para viabilizar e incrementar a produção agrícola no Piauí, assumindo caráter de irrigação suplementar, durante a estação chuvosa, e de irrigação total, na estação seca (Andrade Junior, 2000). A evapotranspiração de referência (ETo) é um fator importante para o dimensionamento de sistemas e manejo de água de irrigação, sendo sua estimativa 
mensal, no âmbito regional, de extrema importância aos estudos de planejamento agrícola (Sousa, 1993).

O termo ETo foi definido por Thornthwaite (1948) como a perda de água de uma extensa superfície vegetada, de porte rasteiro, em fase de desenvolvimento ativo e sem limitação hídrica. Segundo Pereira et al. (1997), a evapotranspiração é controlada pela disponibilidade de energia, pela demanda atmosférica e pelo suprimento de água do solo às plantas. A disponibilidade de energia depende do local e da época do ano. O local é caracterizado pelas coordenadas geográficas (latitude e longitude) e pela topografia da região (altitude).

Existem diversos métodos para se estimar a ETo, sendo que a possibilidade de utilização de cada método depende dos registros dos elementos climáticos disponíveis em determinado local ou região. Como, normalmente, é mais fácil se encontrar ou dispor de dados de temperatura média do ar, na escala mensal, de determinado local ou região, o método de Thornthwaite (1948) tem sido difundido e utilizado para a estimativa de ETo nessas condições.

Apesar de sua extensão territorial, o Estado do Piauí conta com um número limitado de estações que medem ou registram dados de temperatura do ar. Para suprir essa limitação tem-se utilizado a estimativa desses elementos climáticos, com base nas coordenadas geográficas (Pereira et al., 2002). Lima \& Ribeiro (1998) desenvolveram equações empíricas para estimar as temperaturas máximas, mínimas e médias do ar para todo o Estado, baseadas nos valores de latitude, longitude e altitude. A temperatura do ar é, dentre as variáveis meteorológicas, a de maior efeito direto e significativo sobre muitos processos fisiológicos que ocorrem na natureza, influenciando e contribuindo substancialmente para a demanda evapotranspirativa local.

Desta forma, efetuou-se este trabalho com o objetivo de estimar a evapotranspiração de referência mensal para o Estado, tomando-se como modelo as equações de estimativa da temperatura do ar para o Estado do Piauí, propostas por Lima \& Ribeiro (1998).

\section{MATERIAL E MÉTODOS}

A estimativa da evapotranspiração de referência (ETo) mensal foi efetuada a partir das equações empíricas para a estimativa da temperatura do ar para o Estado do Piauí, conforme Lima \& Ribeiro (1998). Os autores utilizaram séries históricas de valores mensais da temperatura do ar de períodos nãouniformizados com, no mínimo, seis anos de observações, em vinte e três estações meteorológicas. Com os dados dessas séries, ajustaram equações pelo método dos mínimos quadrados, obtendo equações de regressão linear múltipla e testaram o método estatístico, apresentado a seguir:

$$
E(Y)=a_{0}+a_{1} X_{1}+a_{2} X_{2}+a_{3} X_{3}
$$

em que:

$\mathrm{Y}$ - temperatura mensal do ar (média, máxima ou mínima) ${ }^{\circ} \mathrm{C}$; $\mathrm{X}_{1}, \mathrm{X}_{2}$ e $\mathrm{X}_{3}$ - latitude do local (min), altitude (m) e longitude do local (min), respectivamente; $a_{0}, a_{1}, a_{2}$ e $a_{3}$ - coeficientes da equação de regressão.

As equações de regressão linear múltipla para se estimar a temperatura do ar (máxima, mínima e média) foram obtidas a partir de dados de algumas estações climatológicas do INMET situadas no Estado (Lima \& Ribeiro, 1998). Por essas equações, as temperaturas máximas, mínimas e médias do ar são estimadas com base na latitude, longitude e altitude locais. Obtiveram-se os dados de latitude, longitude e altitude do Instituto Brasileiro de Geografia e Estatística - IBGE e com os dados de temperatura média do ar estimados, procedeu-se à estimativa da ETo para todos os municípios piauienses, pelo método empírico de Thornthwaite (1948), conforme apresentado em Pereira et al. (1997).

Os valores mensais de ETo foram geoespacializados usando-se o programa computacional Spring v. 4.0 (Câmara et al., 1996). Adotou-se o seguinte procedimento: i) importação das amostras (valores mensais de ETo), no formato de modelo numérico de terreno - MNT; ii) geração de grade retangular, com resolução de $1.000 \times 1.000 \mathrm{~m}$, usando-se como interpolador a média ponderada; iii) geração de grade retangular refinada, com resolução de 500 x 500 m, empregando-se o interpolador bicúbico; iv) recorte do plano de informação usando-se como máscara, o limite estadual; v) fatiamento e associação em classes, com intervalo de $25 \mathrm{~mm}$, na escala mensal, e de $150 \mathrm{~mm}$, na escala anual; vi) tabulação cruzada entre os planos de informação de ETo versus municípios, permitindo estimar-se, para cada município, a área $\left(\mathrm{km}^{2}\right)$ e a porcentagem de ocorrência das diversas classes de ETo, nas escalas mensal e anual.

Com o intuito de homogeneizar as classes de ETo, quando em determinado município ocorressem duas ou mais classes de ETo, estabeleceram-se duas situações: i) situação 1: mudança de classe inferior para classe superior - quando a porcentagem de ocorrência de uma classe inferior à de uma outra classe fosse $\leq$ a $20 \%$, a área de ocorrência da classe inferior seria incorporada à da classe imediatamente superior; ii) situação 2: mudança de classe superior para classe inferior quando a porcentagem de ocorrência de uma classe superior à de uma outra classe fosse $\leq$ a $20 \%$, a área de ocorrência da classe superior seria incorporada à da classe imediatamente inferior. Este procedimento possibilitou a obtenção de mapas de ETo mais uniformes e homogêneos.

\section{RESULTADOS E DISCUSSÃO}

Os valores de ETo mensais e anual para alguns municípios do Estado do Piauí são apresentados na Tabela 1. Os municípios listados estão situados nas diferentes microrregiões do Estado, sujeitos a diferentes regimes hídricos e condições climáticas, de forma a se inferir quanto à magnitude e variabilidade da ETo no Estado como um todo.

Ocorreu uma ampla variação nos valores mensais e anual de ETo nas diferentes microrregiões do Estado. Os menores valores mensais e anual de ETo foram registrados em Pedro II (959,1 mm), na microrregião de Campo Maior, enquanto os maiores foram encontrados em Cajueiro da Praia (1.954,3 mm), na microrregião do Litoral Piauiense. Os dois municípios apresentam longitudes semelhantes e diferença de apenas $2^{\circ}$ 
Tabela 1. Valores mensais e anuais de ETo (mm) em alguns municípios do Estado do Piauí

\begin{tabular}{|c|c|c|c|c|c|c|c|c|c|c|c|c|c|c|c|c|c|}
\hline \multirow{2}{*}{ Municípios $^{1}$} & \multirow{2}{*}{ Lat. } & \multirow{2}{*}{ Long. } & \multirow{2}{*}{$\begin{array}{l}\text { Alt. } \\
\text { (m) }\end{array}$} & \multirow{2}{*}{$\begin{array}{l}\text { Microrregião } \\
\text { Geográfica }^{2}\end{array}$} & \multicolumn{12}{|c|}{ Meses } & \multirow{2}{*}{ Anual } \\
\hline & & & & & $\mathrm{J}$ & $\mathrm{F}$ & M & A & M & $\mathrm{J}$ & $\mathrm{J}$ & $\mathrm{A}$ & $\mathrm{S}$ & $\mathrm{O}$ & $\mathrm{N}$ & $\mathrm{D}$ & \\
\hline Parnaíba & $2^{\circ} 54^{\prime}$ & $41^{\circ} 47^{\prime}$ & 5 & L. Piauiense & 156,2 & 123,2 & 135,3 & 131,9 & 139,5 & 139,3 & 157,8 & 174,1 & 186,7 & 200,7 & 7197,0 & 185,0 & 1926,7 \\
\hline $\begin{array}{l}\text { Cajueiro } \\
\text { da Praia }\end{array}$ & $2^{\circ} 56^{\prime}$ & $41^{\circ} 20^{\prime}$ & 10 & $\begin{array}{l}\text { Litoral } \\
\text { Piauiense }\end{array}$ & 159,2 & 123,6 & 134,5 & 130,2 & 138,4 & 140,0 & 158,1 & 176,6 & 5189,2 & 205,2 & 2 207,9 & 191,6 & 1954,3 \\
\hline M. Alves & $4^{\circ} 10^{\prime}$ & $42^{\circ} 54^{\prime}$ & 50 & B. P. Piauiense & 141,6 & 105,5 & 130,7 & 128,2 & 135,0 & 130,5 & 148,0 & 166,6 & 5185,4 & 195,4 & 4175,5 & 163,9 & 1806,3 \\
\hline Teresina & $5^{\circ} 05^{\prime}$ & $42^{\circ} 48^{\prime}$ & 72 & Terecing & 141,2 & 115,3 & 132,0 & 128,7 & 136,6 & 132,2 & 147,3 & 170,9 & 192,7 & 201,2 & 2181,2 & 162,1 & 1841,3 \\
\hline $\begin{array}{l}\text { Campo } \\
\text { Maior }\end{array}$ & $4^{\circ} 50^{\prime}$ & $42^{\circ} 10^{\prime}$ & 125 & $\begin{array}{l}\text { Campo } \\
\text { Maior }\end{array}$ & 141,3 & 104,8 & 128,9 & 123,9 & 129,6 & 125,4 & 138,6 & 157,7 & 7176,5 & 190,2 & 2177,8 & 164,0 & 1758,7 \\
\hline Piripiri & $4^{\circ} 16^{\prime}$ & $41^{\circ} 47^{\prime}$ & 170 & B. P. Piaui & 138,3 & 101,1 & 122,4 & 116,6 & 119,7 & 114,6 & 127,2 & 141,0 & 158,7 & 177,3 & 31608 & 163,6 & 51650,2 \\
\hline $\begin{array}{l}\text { Angical } \\
\text { do Piauí }\end{array}$ & $6^{\circ} 05^{\prime}$ & $41^{\circ} 28^{\prime}$ & 192 & $\begin{array}{l}\text { 1. P. } \\
\text { iauiense }\end{array}$ & 132,5 & 109,7 & 126,0 & 121,1 & 125,7 & 118,0 & 128,4 & 147,9 & 171,2 & 182,8 & 8163,8 & 149,9 & 1677,0 \\
\hline Picos & $7^{\circ} 05^{\prime}$ & $41^{\circ} 28^{\prime}$ & 206 & $i \cos$ & 144,8 & 118,9 & 134,1 & 125,7 & 132,5 & 129,3 & 134,4 & 163,7 & 7185,6 & 199,1 & 1192,8 & 163,9 & 1824,8 \\
\hline $\begin{array}{l}\text { Colônia } \\
\text { do Gurguéia }\end{array}$ & $8^{\circ} 11^{\prime}$ & $43^{\circ} 48^{\prime}$ & 216 & Bertolínia & 124,0 & 106,5 & 127,5 & 122,6 & 127,9 & 119,6 & 127,7 & 156,2 & 186,5 & 191,8 & 8157,7 & 134,7 & 1682,8 \\
\hline $\begin{array}{l}\text { Cristino } \\
\text { Castro }\end{array}$ & $8^{\circ} 49^{\prime}$ & $44^{\circ} 13^{\prime}$ & 239 & $\begin{array}{l}\text { A. Médio } \\
\text { Gurguéia }\end{array}$ & 119,5 & 104,1 & 126,5 & 122,0 & 127,0 & 117,6 & 124,9 & 153,8 & 186,0 & 189,5 & 5150,9 & 128,0 & 1649,8 \\
\hline Itaueira & $7^{\circ} 36^{\prime}$ & $43^{\circ} 02^{\prime}$ & 258 & Floriano & 126,3 & 106,9 & 125,1 & 119,1 & 123,1 & 114,6 & 120,7 & & 5170,9 & 181,2 & 2157,3 & 139,6 & 51629 \\
\hline $\begin{array}{l}\text { Valença } \\
\text { do Piauí }\end{array}$ & $6^{\circ} 24^{\prime}$ & $41^{\circ} 45^{\prime}$ & 308 & $\begin{array}{l}\text { alença } \\
\text { Piauí }\end{array}$ & 131,0 & 107,7 & 121,4 & 113,7 & 115,7 & 107,5 & 114,0 & 129,5 & 5150,5 & 168,1 & 1159,0 & 149,4 & 1567,6 \\
\hline $\begin{array}{l}\text { B. Grande } \\
\text { do Ribeiro }\end{array}$ & $7^{\circ} 51$ & $45^{\circ} 13$ & 325 & $\begin{array}{l}\text { rnaíba } \\
\text { ense }\end{array}$ & 108,5 & 95,7 & 115,7 & 112,3 & 111,8 & 98,1 & 106,9 & 121,0 & 148,4 & 156,6 & 6118,3 & 115,7 & 1408,9 \\
\hline $\begin{array}{l}\text { S. Raimundo } \\
\text { Nonato }\end{array}$ & $9^{\circ} 01^{\prime}$ & $42^{\circ} 42^{\prime}$ & 332 & $\begin{array}{l}\text { S. Raimundo } \\
\text { Nonato }\end{array}$ & 121,0 & 102,4 & 121,5 & 113,4 & 116,9 & 108,5 & 111,7 & 139,7 & 7170,6 & 183,0 & $\begin{array}{lll}0 & 159,1\end{array}$ & 133,1 & 1581,0 \\
\hline Paulistana & $8^{\circ} 09^{\prime}$ & $41^{\circ} 09^{\prime}$ & 359 & A. M. Canindé & 133,2 & 110,0 & 124,2 & 113,5 & 116,1 & 110,6 & 112,7 & 136,7 & 7160,5 & 179,2 & 2173,7 & 150,3 & 1620,6 \\
\hline C. do Piauí & $10^{\circ} 39^{\prime}$ & $45^{\circ} 11$ & 469 & $\begin{array}{l}\text { C. do Extremo } \\
\text { Sul Piauiense }\end{array}$ & 96,6 & 78,4 & 109,8 & 104,7 & 103,8 & 88,0 & 91,3 & 110,6 & 5144,6 & 153,2 & 2110,6 & 100,1 & 1291,6 \\
\hline Pio IX & $6^{\circ} 50^{\prime}$ & $40^{\circ} 35^{\prime}$ & 495 & Pio IX & 117,7 & 94,1 & 103,7 & 92,5 & 89,5 & 80,6 & 81,9 & 93,2 & 2114,8 & 141,8 & 8142,3 & 139,3 & 31291,4 \\
\hline Pedro II & $4^{\circ} 25^{\prime}$ & $41^{\circ} 28^{\prime}$ & 603 & Campo Maior & 97,8 & 71,2 & 84,9 & 76,7 & 68,1 & 55,4 & 60,5 & 57,3 & 73,5 & 100,7 & $7 \quad 93,9$ & 119,0 & 959,1 \\
\hline D. Arcoverde & $9^{\circ} 20^{\prime}$ & $42^{\circ} 26^{\prime}$ & 740 & $\begin{array}{l}\text { S. Raimundo } \\
\text { Nonato }\end{array}$ & 94,9 & 81,1 & 94,8 & 84,9 & 78,1 & 63,8 & 64,0 & 70,4 & 493,8 & 116,3 & $\begin{array}{ll}3 & 99,0\end{array}$ & 104,8 & 81045,9 \\
\hline Máximo & & & & & 159,2 & 123,6 & 135,3 & 131,9 & 139,5 & 140,0 & 158,1 & 176,6 & 6192,7 & 205,2 & 2207,9 & 191,6 & 61954,3 \\
\hline Mínimo & & & & & 94,9 & 71,2 & 84,9 & 76,7 & 68,1 & 55,4 & 60,5 & 57,3 & 73,5 & 100,7 & $7 \quad 93,9$ & 100,1 & $1 \quad 959,1$ \\
\hline Média & & & & & 127,7 & 103,2 & 121,0 & 114,8 & 117,6 & 110,2 & 118,7 & 137,4 & & & & & 21587,7 \\
\hline
\end{tabular}

na latitude, que deve ter causado pequena influência na estimativa dos valores de ETo, já que existe relação entre a latitude e a irradiância global na expressão da temperatura média do ar (Pereira et al., 2002). A diferença na altitude média dos municípios ( $\cong 503 \mathrm{~m}$ ) é que foi o fator decisivo para essa variação nos valores mensais de ETo, uma vez que, à medida em a altitude se eleva normalmente os valores de temperatura média tendem a ser menores, contribuindo para a redução da demanda evapotranspirativa da região (Lima \& Ribeiro, 1998; Pereira et al., 2002). De fato, a ETo anual do município de Parnaíba, com $5 \mathrm{~m}$ de altitude média, foi de $1.926,7 \mathrm{~mm}$, enquanto a ETo anual do município de Dirceu Arcoverde, com $740 \mathrm{~m}$ de altitude média, foi de $1.045,9 \mathrm{~mm}$, indicando uma redução de $119,8 \mathrm{~mm}$ na ETo anual para cada $100 \mathrm{~m}$ de acréscimo na altitude média (razão de $\cong 1,2 \mathrm{~mm}$ de ETo $\mathrm{m}^{-1}$ de altitude).

Considerando-se os municípios por região agroecológica do Estado, constatou-se variação nos valores médios mensais de ETo. Por exemplo, agrupando-se os municípios de Parnaíba, Miguel Alves e Piripiri, que representam a condição hídrica e climática da região norte do Estado, eles mostram valores médios anuais de ETo de 1.794,4 mm. Por sua vez, juntando-se os municípios de Dirceu Arcoverde, Pio IX, Paulistana e São Raimundo Nonato, que representam a condição hídrica e climática da região semi-árida do Estado, estes indicam valores médios anuais de ETo de 1.384,7 mm. A ETo média anual da região semi-árida foi cerca de 409,7 $\mathrm{mm}$ inferior à da região norte do Estado; contudo, o balanço hídrico climatológico anual da região semi-árida é extremamente desfavorável em relação à região norte do Estado devido, notadamente, às diferenças nos valores de precipitação média anual obtidos entre as duas regiões. Na região norte do Estado, a precipitação média anual se situa em torno de $1.200 \mathrm{~mm}$ anuais, enquanto na região semi-árida chove, em média, apenas $600 \mathrm{~mm}$ anuais (RNA, 2003), agravando bastante os problemas de suplementação hídrica dessa região para consumo humano, animal e agricultura.

A Tabela 2 apresenta a percentagem média de ocorrência das classes de ETo mensal no Estado do Piauí. Em termos médios, predominam as classes de ocorrência de 100 - 125, 125 - 150 e de 150 - 175 mm que, juntas, totalizam $84,4 \%$ da área do 

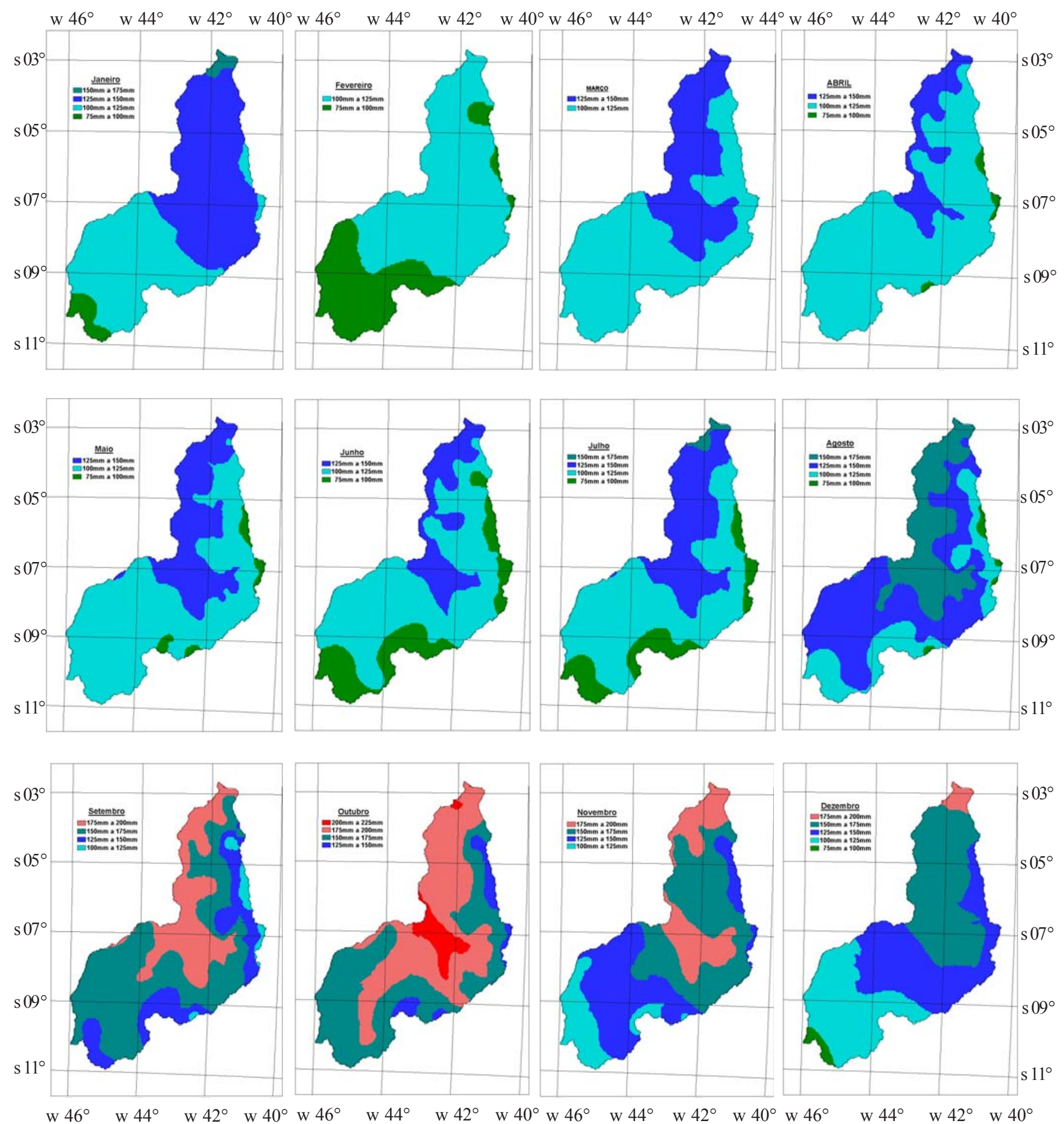

Figura 1. Mapas de ETo mensal para o Estado do Piauí

Estado e equivalem a uma variação de 3,3 a 5,8 mm em termos de ETo média diária, em praticamente toda a área do Estado.

A classe de ETo de 75 a $100 \mathrm{~mm}$ ocorre em apenas 4,37\% da área do Estado, praticamente em todos os meses do ano, à exceção de setembro a novembro, comportamento este decorrente dos baixos valores mensais de ETo registrados nos municípios situados nas regiões sul, sudeste e leste do Estado, que apresentam as maiores altitudes médias do Estado (Tabela 1); entretanto, a classe dos maiores valores de ETo (200 a 225 $\mathrm{mm}$ ) engloba apenas $0,62 \%$ do Estado e predomina nos meses de outubro e novembro, período de maior demanda hídrica no Estado, significando, que uma pequena área do Estado apresenta valores de ETo máxima diária na faixa de 6,7 a 7,5 mm e deverá necessitar de uma suplementação hídrica elevada via água de irrigação. A Figura 1 permite uma visualização melhor das áreas de ocorrência dessas classes de ETo em todo o Estado.

A ETo mensal indica ampla variação ao longo do ano em todo o Estado do Piauí, conforme variam os valores de temperatura média do ar e o regime de chuvas da região 
Tabela 2. Percentagem média de ocorrência das classes de ETo (mm) mensal no Estado do Piauí

\begin{tabular}{lrrrrrr}
\hline \multirow{2}{*}{ Meses } & \multicolumn{6}{c}{ Classes de ETo (mm) } \\
\cline { 2 - 7 } & $75-100$ & $100-125$ & $125-150$ & $150-175$ & $175-200$ & $200-225$ \\
\hline Janeiro & 2,29 & 23,53 & 70,84 & 3,34 & 0,00 & 0,00 \\
Fevereiro & 16,91 & 83,09 & 0,00 & 0,00 & 0,00 & 0,00 \\
Março & 0,01 & 47,96 & 52,03 & 0,00 & 0,00 & 0,00 \\
Abril & 1,40 & 74,95 & 23,65 & 0,00 & 0,00 & 0,00 \\
Maio & 3,15 & 52,48 & 44,38 & 0,00 & 0,00 & 0,00 \\
Junho & 15,23 & 57,33 & 27,45 & 0,00 & 0,00 & 0,00 \\
Julho & 11,33 & 42,31 & 42,90 & 3,46 & 0,00 & 0,00 \\
Agosto & 1,15 & 19,22 & 35,69 & 43,94 & 0,00 & 0,00 \\
Setembro & 0,00 & 2,38 & 18,50 & 40,88 & 38,23 & 0,01 \\
Outubro & 0,00 & 0,00 & 4,59 & 31,79 & 56,23 & 7,40 \\
Novembro & 0,00 & 5,55 & 17,71 & 47,45 & 29,22 & 0,05 \\
Dezembro & 0,98 & 13,10 & 25,62 & 56,11 & 4,19 & 0,00 \\
\hline Média & 4,37 & 35,16 & 30,28 & 18,91 & 10,66 & 0,62 \\
\hline
\end{tabular}

(Medeiros, 1996). Os valores mínimos ocorrem nos meses de fevereiro a julho, com predomínio da classe de ETo de 100 a $125 \mathrm{~mm}$, enquanto os valores máximos se estendem de agosto a dezembro, com predomínio da classe de ETo de 150 a $175 \mathrm{~mm}$. Os períodos de ocorrência das classes de ETo, com valores máximos e mínimos, correspondem justamente aos períodos de ocorrência da estação chuvosa e seca, respectivamente, sendo também um reflexo natural da variação espacial e da grande amplitude da temperatura média mensal nas diferentes regiões do Estado, a qual se acentua à medida que se afasta do litoral para o interior (Tubelis \& Nascimento, 1987).

Os mapas geoespacializados dos valores de ETo mensais gerados, possibilitam análises da ETo de todos os municípios do Estado e a realização de estudos de planejamento agrícola, mais elaborados notadamente em agricultura irrigada.

\section{CONCLUSÕES}

1. As estimativas de ETo mensais para os municípios do Estado do Piauí apresentam dependência da localização geográfica (latitude e longitude), sobretudo, da topografia local (altitude).
2. Em termos médios, predominam as classes de ocorrência de 100 a $125 \mathrm{~mm} ; 125$ a $150 \mathrm{~mm}$ e de 150 a $175 \mathrm{~mm}$ que, juntas, totalizam $84,4 \%$ da área do Estado, representando uma variação de 3,3 a 5,8 $\mathrm{mm}$ em termos de ETo média diária, em praticamente toda a área do Piauí.

\section{LITERATURA CITADA}

Andrade Junior, A.S. Viabilidade da irrigação, sob risco climático e econômico, nas microrregiões de Teresina e Litoral Piauiense. Piracicaba: ESALQ, 2000. 556p. Tese Doutorado Câmara, G.; Souza, R.C.M.; Freitas, U.M.; Garrido, J. Spring: Integrating remote sensing and GIS by object - oriented data modeling. Computers \& Graphics, New York, v.20, n.3, p.395-403, 1996.

Lima, M.G. de; Ribeiro, V.Q. Equações de estimativa da temperatura do ar para o Estado do Piauí, Brasil. Revista Brasileira de Agrometeorologia, Santa Maria, v.6, n.2, p.221227, 1998.

Medeiros, R.M. Isoietas médias mensais e anuais do Estado do Piauí. Teresina: Secretaria de Agricultura, Abastecimento e Irrigação, Departamento de Hidrometeorologia, 1996. 24p.

Ortolani, A.A.; Camargo, M.B.P. Influência dos fatores climáticos na produção. In: Castro, P.R.C.; Ferreira, S.O.; Yamada, T. Ecofisiologia da produção agrícola. Piracicaba: Associação Brasileira para Pesquisa da Potássio e do Fosfato, 1987, p.71-81.

Pereira, A.R.; Angelocci, L.R.; Sentelhas, P.C. Agrometeorologia: Fundamentos e aplicações práticas. Guaíba: Agropecuária, 2002, p.105-129.

Pereira, A.R.; Villa Nova, N.A.; Sediyama, G.C. Estimativa de evapotranspiração. Piracicaba: FEALQ, 1997. p.41-99.

RNA - Rede Nacional de Agrometeorologia. Mapas de precipitação mensal do Estado do Piauí. http:// www.agricultura.gov.br/rna. Acessado em 23/08/2003.

Sousa, E.F. Modelo computacional aplicativo ao manejo e planejamento de irrigação. Viçosa: UFV 1993. 65p. Dissertação Mestrado.

Thornthwaite, C.W. An approach toward a rational classification of climate. Geographical Review, New York, v.38, n.1, p.5594, 1948.

Tubelis, A.; Nascimento, T. Meteorologia descritiva: fundamentos e aplicações. São Paulo: Nobel, 1987. $221 \mathrm{p}$. 